\title{
Prior Authorization and Clopidogrel Use-The Truth Lies in the Details
}

\author{
Mark A. Jackson, RPh, BScPhm, BComm; Kathleen A. Fairman, MA; \\ and Frederic R. Curtiss, PhD, RPh, CEBS
}

$\mathrm{I}$ $\mathrm{n}$ the midst of the high-stakes game to reduce heart attacks, Jackevicius et al. reported in October 2008 that "removal of a [prior authorization (PA)] program led to improvement in timely access to clopidogrel for coronary stenting and improved cardiovascular outcomes." In fact, the PA requirement was replaced with a "limited use" policy for clopidogrel (Plavix) in the Canadian province of Ontario in September 2003, and this policy change was associated with a 4-point decline in major cardiovascular events measured 1 year after hospitalization for acute myocardial infarction and percutaneous coronary intervention (PCI) with stenting among patients aged 65 years or older. Rates of the primary cardiovascular outcome-a composite measure of death, recurrent acute myocardial infarction, repeat PCI, and coronary-artery bypass grafting-were $15 \%$ in the 41 -month PA period from April 2000 through August 2003 versus 11\% in the 19-month limited-use period from September 2003 through March $2005(P=0.02)$. Rates of death during the PA period and the limited-use period did not differ significantly (5\% vs. 4\%, respectively; $P=0.42$ ).

Jackevicius et al. attributed the improvement in cardiovascular outcomes to increased use of clopidogrel following relaxation of the PA requirement. The percentage of patients who used the Ontario Drug Benefit (ODB) program to fill prescriptions for clopidogrel in the first 30 days following hospital discharge for myocardial infarction and PCI with stenting increased from 35\% under PA to $88 \%$ under the limited-use policy, and the median time from discharge to the first clopidogrel claim declined from 9 days to 0 days. ${ }^{1}$

Not surprisingly given the morbidity, mortality, and economic cost of heart disease, estimated to have resulted in the deaths of approximately 43,000 Canadians and 514,000 Americans in $2002,{ }^{2}$ the report by Jackevicius et al. garnered media attention. The popular press reported that clopidogrel "flowed more freely to stent patients and outcomes improved." One headline stated that "Policy Change Improves Cardiovascular Outcomes," and a press release disseminated by the lead author's academic institution declared that "Faster Medication=Fewer Heart Attacks." Although the study's lead author acknowledged that PA policies vary by payer, she contended in an interview conducted shortly after publication of the study that its findings had broad applicability in the United States. ${ }^{6}$ However, as Fairman and Curtiss pointed out in their March 2008 review of a report on value-based insurance design, press accounts rarely contain the details necessary for a decision-maker to evaluate a study report's validity, much less its applicability to populations with clinical or demographic characteristics unlike those of the study sample. ${ }^{7}$ Careful examination of the study's context, sample and methods is warranted.

\section{The "PA" Process Was Atypically Burdensome}

Close examination of Ontario's complex process of drug coverage and reimbursement suggests that the "PA" requirement studied by Jackevicius et al. differed substantially from PA as typically administered in the United States. The ODB formulary provides access to over 3,400 medications. Drugs not listed in the formulary may be requested by a prescriber in writing through a process known as the Individual Clinical Review (ICR) or simply "Section 8," 8,9 in reference to the section of the Ontario Drug Benefit Act that originally defined the ICR process. Requests for ICR coverage are reviewed on a case-by-case basis. ${ }^{8,9}$

Prior to September 4, 2003, clopidogrel was not listed in the ODB formulary. ${ }^{8}$ The only mechanism for reimbursement of the drug under ODB was through the ICR process. In 2003, this process required the physician to provide a written request (usually in the form of a letter) containing a "concise clinical description and therapeutic plan" including a specific diagnosis, objective evidence of drug efficacy (if the patient had already been taking the drug), details of the dosage, duration and response for formulary alternatives, concomitant drug therapy, laboratory results, etc. ${ }^{8}$ The administrative burden of Ontario's ICR program is compounded by the fact that each ICR request and approval is both drug and strength specific. In the event of dose changes requiring a different strength or dosage form of a given drug, a new ICR request is generally required. 8,9

By September 2005, ODB had developed a standard template form and several drug-specific forms to streamline the ICR process to some degree, ${ }^{9}$ but at the time of the clopidogrel coverage change, the process was primarily manual. ODB administrative data for fiscal year 2004 (April 1, 2003 through March 31, 2004) show that 41,936 requests for clopidogrel coverage were received, and ODB approved 36,339 of those requests (86.7\%), at an expense of CAD $\$ 24.4$ million (CAD\$671 clopidogrel cost per PA approval). ${ }^{10}$

However, the typical response time for these requests was lengthy. In ODB's fiscal year 2002, the average turnaround for ICR requests was 15.3 days, with $33 \%$ of requests taking in excess of 3 weeks to resolve. ${ }^{11}$ Since 2002, ODB no longer reports an average turnaround. By fiscal year 2004, 44\% of all ICR requests took in excess of 3 weeks to resolve. ${ }^{10}$ These data suggest that the problem of excessive waits associated with the ICR process 
may have been getting worse. Consistent with these reports of the overall poor performance of the ICR system, the upper end of the interquartile range for time from hospital discharge until first clopidogrel use in the Jackevicius study was 39 days, indicating that under ICR $25 \%$ of study patients experienced a delay of more than 5.5 weeks before receiving clopidogrel. ${ }^{1}$

In contrast to the "PA" (ICR) process studied by Jackevicius et al., a typical PA process in the United States involves completion of a telephone call or 1-page form, sometimes including preprinted diagnoses specific to drug and indication. ${ }^{12-17}$ Although virtually no systematic investigations of PA response times are available in the peer-reviewed literature, payers report standard response times ranging from 2-4 days, faster for more urgent requests..$^{14,15,17}$ An operational and performance analysis of an Iowa Medicaid PA program in which 93\% of PA requests were made by telephone reported a mean response time of 73 minutes for new requests. ${ }^{18}$

\section{"PA" Was Not "Removed:" The Limited-Use Process Was Actually a Form of PA}

The "limited-use" status that replaced ICR for certain users of clopidogrel on September 4, 2003, in Ontario resembles a typical PA intervention in the United States in its use of defined criteria for coverage and in terms of the time involved. Under the limiteduse provision, drugs are on formulary, but the patient must meet specific predefined clinical criteria for coverage (Table 1).

The ODB's change to limited-use status for clopidogrel was apparently an attempt to improve efficiency in the administrative process and facilitate access to the drug for acute indications. Whatever the motivation, the limited-use process that has been in effect in Ontario, Canada, since the "removal" of PA requires the prescriber to record a number corresponding to an applicable criterion on the prescription order form. The dispensing pharmacist enters this number in the prescription claim record for adjudication. In addition to the 3 -digit limited-use code provided in the criteria, pharmacies are also required to submit a special authorization number corresponding to the hospital in which the patient was hospitalized. ${ }^{8,19}$ Even this allegedly more liberal process has been criticized both for its inconvenience to prescribers (pharmacists must frequently contact prescribers to verify invalid or omitted codes prior to submitting a claim to ODB), and for the intentional provision of incorrect codes in order to achieve coverage for patients. ${ }^{20}$ Coverage of clopidogrel for indications outside of the criteria listed in Table 1, such as "secondary prevention of ischemic events for patients intolerant or allergic to ASA [aspirin] or ticlodipine," continues to be available only through the ODB's ICR program..$^{21,22}$

\section{The Clopidogrel Utilization Measure Was Inaccurate}

A fact that is too often forgotten in interpreting analyses of administrative claims is that researchers do not have access to all utilization of a drug or service, only to the utilization billed

\section{TABLE 1) ODB Coverage Criteria for Clopidogrel} Beginning September 2003

\begin{tabular}{l|l}
\hline Limited Use Code & \multicolumn{1}{c}{ Criteria } \\
\hline 375 & $\begin{array}{l}\text { For patients immediately post-hospitalization } \\
\text { non-ST for }\end{array}$ \\
\hline 376 & For patients immediately pre- or post-PCI ${ }^{\mathrm{d}}$ \\
\hline
\end{tabular}

a Derived from the Ontario Ministry of Health and Long Term Care. Ontario Drug Benefit Formulary/Comparative Drug Index, Edition No. 38, Update B. 8,19

${ }^{b}$ The first prescription must be written by a physician based at the hospital where the patient was hospitalized.

'ACS, as defined by the CURE study, includes hospitalized patients with unstable angina or non-ST segment elevation myocardial infarction.

dTherapy may be initiated up to 10 days prior to PCI.

ACS = Acute Coronary Syndrome; $C U R E=$ Clopidogrel in Unstable Angina to

Prevent Recurrent Events; $O D B=$ Ontario Drug Benefit; $P C I=$ percutaneous coronary intervention.

to the particular payer that served as the data source for the study. To the credit of Jackevicus et al., they acknowledge in their study report that they "were not able to ascertain whether certain patients elected to pay for the medication directly, were given samples, or had a private drug plan that covered the medication." What they do not acknowledge, however, is how serious this study limitation is in light of Ontario's drug coverage structure and the incentive provided to patients to obtain clopidogrel by a means other than the slow ICR process.

The drug reimbursement system in Ontario is complex and not readily transferable to the United States. An especially significant difference between the 2 countries is the overlap of public and private systems in Ontario. The ODB program primarily provides drug coverage for those aged 65 and older and for those receiving social assistance (i.e., low income). Additionally, a means-based program is available for those whose out-of-pocket drug expenses are high relative to their income. ${ }^{8,9,22,23}$ Others are often covered by employer-sponsored drug plans, individual drug plans, or through federal programs targeted to specific groups (e.g., First Nations and Veterans Affairs). Dual coverage is possible, but its incidence is poorly understood. In some cases, Ontarians may be able to retain employer-sponsored benefits after retirement and beyond age 65. Federal programs such as those for Veterans' Affairs Canada and for First Nations also continue coverage regardless of age. Paterson et al.'s recent study of dual coverage among seniors in Ontario estimated that, from 2000 to $2005,15 \%-20 \%$ of Ontario senior citizens filled at least 1 prescription that was paid by a private insurer, with new drugs "represented disproportionately in private drug claims" rather than in the ODB database. ${ }^{24}$

The combination of the administrative burden of the ICR process and unacceptably long wait times for potentially urgent medications meant that the ICR process was not accessed unless absolutely necessary. As a practical matter, many patients prescribed clopidogrel could easily access the drug through a private 
reimbursement source rather than wait for ICR approval. Thus, the effect of dual coverage on the problem of "data capture"- the degree to which claims paid by ODB failed to provide a complete picture of clopidogrel utilization-was particularly problematic.

Paterson et al.'s analysis of clopidogrel use by Ontario enrollees aged 65 years or older who were dually covered-meaning that they received prescription drug coverage both through ODB and a private insurance plan-provides a sense of the scope of the problem. In the second quarter of 2003, just prior to the change from ICR to limited use, clopidogrel claims per 1,000 prescription drug utilizers (those who filled at least 1 prescription for any medication) by payer were 6.3 for ODB and 53.2 for private insurance. One year later, in the second quarter of 2004, clopidogrel use rates per 1,000 utilizers were 16.3 for ODB and 65.0 for private insurance..$^{24,25}$ Thus, for those with dual ODB-private coverage, ODB paid for and recorded in its database only about $11 \%$ of clopidogrel use under ICR ("PA") and only about 20\% under limited use.

Paterson et al.'s findings indicate that a substantial portion of clopidogrel use in Ontario was not captured in the dataset used by Jackevicius et al. More important, Paterson et al.'s findings also suggest a proportional shift in payment source. Following the change to limited use, a portion of the clopidogrel claims that would have been paid by private insurance were instead paid by ODB. Thus, an unknown amount of the change in clopidogrel utilization measured by Jackevicius et al. represents nothing more than a shift in payer source from private insurance (claims data not captured) to ODB (claims data captured), and the actual degree of increase in utilization of clopidogrel in the Jackevicius et al. sample is unknown.

\section{The Observed Outcomes Could be the Effects of a Policy Change, Improvements in Quality of Care or Something Else - Use of Drug-Eluting Stents Skyrockets}

Interrupted time series, the statistical technique employed by Jackevicius et al., quantifies trends in a phenomenon of interest over time, comparing events in the time period before and after an intervention. In an interrupted time series that lacks a comparison group, a key question is whether the pre-intervention trend adequately represents the equivalent of a true comparison group, that is, what the post-intervention trend would have been if the intervention had not taken place. ${ }^{26}$ Times series analyses lacking comparison groups are especially vulnerable to the problem of coincident events-other changes taking place simultaneously with the intervention but not controlled in the analysis. ${ }^{26}$ Changes taking place from the "PA" period to the limited-use period, but not controlled in the Jackevicius et al. analysis, included reductions in the baseline prevalence of several chronic comorbidities among study subjects (all $P<0.001$ ); these include diabetes mellitus (declined from $17 \%$ to $13 \%$ ), cardiac dysrhythmia (declined from 13\% to 9\%), and hypertension (declined from 33\% to 28\%). ${ }^{1}$
A much larger threat to the validity of the results attributed to clopidogrel access by Jackevicius et al. was the coincident explosion in the use of drug-eluting stents in PCI procedures, beginning at approximately the start of the limited-use period. Given the association between drug-eluting stents and reduction in risk of target-vessel revascularization after stenting, ${ }^{27}$ this major change in practice patterns was likely, to an unknown extent, to be responsible for the changes in cardiovascular outcomes observed in the Jackevicius et al. study. Jackevicius et al. stated that drug-eluting stents were not introduced in Canada until 2002. Actually, a sirolimus-eluting stent was not approved for use in Canada until late in 2002 (November), and a paclitaxeleluting stent was not approved until September 2003. ${ }^{28}$ Drug eluting stents were therefore uncommon in what Jackevicius et al. describe as the clopidogrel PA period.

Use of drug-eluting stents began to skyrocket at the end of calendar year 2003. Jackevicius et al. report that "drug-eluting stents comprised approximately $40 \%$ of stent use in the cohort beginning in the prior-authorization period." Actually, the indication that the $40 \%$ rate of stent use began in the "prior-authorization" period is potentially misleading; the data reported in the Appendix for the reference for this statement are shown only for the months of December 2003 through March 2005, all after "removal" of the "PA" for clopidogrel, with a mean 38\% use of drug-eluting stents at the time of PCI in Ontario, Canada. ${ }^{29}$ In the United States, the use of drug-eluting stents as a proportion of all stent procedures increased dramatically in just 8 months from 2.5\% in April 2003 to 54.9\% in December 2003.30 In Ontario, funding restrictions may have resulted in a slower uptake of drug-eluting stents ${ }^{31}$ with Tu et al. reporting that $45 \%$ of PCIstent patients received drug-eluting stents in December 2003. ${ }^{29}$

While Jackevicius et al. acknowledge that this factor "potentially confounds our results," they do not report the proportion of patients in the 2 periods that received drug-eluting stents and dismiss the apparent difference in the 2 study periods by stating that "the use of drug-eluting stents has a modest effect on reducing target-vessel revascularization and has not been shown in clinical trials to reduce reinfarction."1 This assessment discounts the results reported by Tu et al. (2007), who found a significantly lower 2-year rate of target-vessel revascularization for patients receiving drug-eluting stents as compared with a propensity score-matched cohort of patients receiving bare-metal stents in Ontario, Canada, between December 1, 2003, and March 31, 2005 (7.4\% vs. $10.7 \%, P<0.001) .{ }^{27}$

This characterization of the facts by Jackevicius et al. regarding the use of drug-eluting stents in Ontario, Canada, also fails to mention that while Tu et al. did find a nonsignificant difference in myocardial infarctions between their drug-eluting stent and bare-metal stent cohorts, 3 of the 4 outcome measures favored drug-eluting stents. In addition to a lower rate of target-vessel revascularization, Tu et al. found a lower 2-year rate of death with drug-eluting stents $(4.3 \%$ vs. $6.1 \%, P<0.001)$ and a lower 
combined rate of death or reinfarction $(9.3 \%$ vs. $10.5 \%$, $P=0.02) .{ }^{27}$

Absent a comparison group, it is also difficult to determine whether other medical innovations or improvements in quality of care for cardiac diseases affected the changes in cardiovascular outcomes measured by Jackevicius et al. For example, serotonin receptor reuptake inhibitors (SSRIs) have antiplatelet properties. ${ }^{32}$ The effect is sufficient to cause Glassman and Bigger (2007) to propose that studies of outcomes in patients with drug-eluting stents should include "surveillance for SSRI-clopidogrel interactions." ${ }^{33}$ The use of SSRIs also has been shown to reduce the rate of death and recurrent myocardial infarction in depressed patients following myocardial infarction. ${ }^{34}$

\section{Clinical and Cost Outcomes - Value for Money in Antiplatelet Therapy}

Although recognizing the limits of their observational research design, Jackevicius et al. argue that "the likelihood of a true causal association [between increased clopidogrel use and improved cardiovascular outcomes] is strengthened by the striking temporal inverse correlation between the increased use of clopidogrel and the decreased [cardiovascular] event rate, the biologic plausibility around this observation, and its consistency with current evidence about the type of benefits in clinical outcomes that are expected with clopidogrel."1 The question of biologic plausibility is indeed particularly important when evaluating trend data.

The evidence that we have in hand today calls for lifelong use of aspirin (acetylsalicylic acid, or ASA, in Canada) in acute coronary syndrome (ACS) patients (i.e., secondary prevention) at a dose of 162-325 mg per day, as both a loading dose and a maintenance dose, with the addition of clopidogrel for 9-12 months at $300 \mathrm{mg}$ initially (loading dose) and $75 \mathrm{mg}$ per day thereafter. ${ }^{35}$ For secondary prevention in PCI patients, aspirin should also be used lifelong at 162-325 mg per day initially and thereafter. Clopidogrel should be used at 300-600 mg as a loading dose and $75 \mathrm{mg}$ daily for 9-12 months after PCI. For other cases of secondary prevention in patients with cardiovascular disease, there are not sufficient data to support the addition of clopidogrel to aspirin.

Clopidogrel alone is an expensive alternative to aspirin; aspirin costs less than 5 cents per day of therapy, ${ }^{36}$ about $1 \%$ of the cost of the highly-advertised clopidogrel, which had an actual average discounted cost per day of US $\$ 4.40$ at year-end 2008. ${ }^{37}$ The "cost comparison of antiplatelet drugs" in the present ODB "Request for Plavix (clopidogrel)" ICR form shows an annual cost of CAD $\$ 5.37$ for aspirin (325 mg enteric coated) versus CAD $\$ 876.00$ for Plavix. ${ }^{21}$ For primary prevention of cardiovascular events, there is no evidence that adding clopidogrel to aspirin offers any advantage over aspirin alone, and its use increases the risk of bleeding. ${ }^{38}$ There are no data on the safety of the combined use of aspirin and clopidogrel for longer than 30 days after acute myocardial infarction or beyond 12 months after ACS. ${ }^{38}$

\section{Effects of PA or Step-Therapy Interventions - The Truth Lies in the Details}

Gleason $^{39}$ and Curtiss $^{40}$ observed previously that managed care pharmacy interventions are not homogenous, and the effects of a PA or step-therapy intervention depend upon the details of the structure and operation of the intervention. Curtiss pointed specifically to population-based observational research performed in Canada that compared step-therapy programs in 2 different provinces for the period from January 1996 to November 2002. ${ }^{41}$ The more restrictive step-therapy program in British Columbia placed cyclooxygenase 2 (COX-2) inhibitors as fourth-line therapy after at least 3 nonsteroidal anti-inflammatory drugs (NSAIDs), compared with the program in Ontario that recommended steptherapy for COX-2 inhibitors. The "special authority approval" required in the British Columbia program was associated with a $25 \%$ increase in prevalence of use of NSAIDs, including COX-2 inhibitors (from $8.7 \%$ to $10.9 \%$ ) in persons aged 66 years or older versus a $51 \%$ increase in the prevalence of use of NSAIDs (from $10.9 \%$ to $16.5 \%$ ) in Ontario. ${ }^{41}$ In addition to the likely higher unfavorable clinical and cost outcomes from adverse cardiovascular events associated with the use of rofecoxib ${ }^{42}$ the rate of hospital admissions due to gastrointestinal (GI) hemorrhage increased significantly in Ontario by about $16 \%$, or a rate of 2 admissions per 10,000 older adults above the expected value $(P<0.01){ }^{41}$ There was no increase in hospital admissions per 10,000 older adults in British Columbia with its more restrictive step-therapy intervention for COX-2 inhibitors, a lower overall absolute rate of use of all NSAIDs, and lower rate of increase in the use of all NSAIDs following the market introduction of the COX-2 drugs. ${ }^{41}$ This study provides the "flip side" of the issue studied by Jackevicius et al. - that a well-run program to restrict medication use to patients most likely to benefit from it has the potential to provide not only cost savings but, more importantly, a measure of safety in the use of newly approved medications.

\section{Balancing Access and Safety and the Potential Price of Inaction}

In evaluating studies of the purported negative consequences of $\mathrm{PA}$, it is important to remember that the clinical and economic consequences of failing to require prior authorization of some drugs may be high. A case in point is provided by Choudhry et al.'s (2008) analysis of clopidogrel use by lower-to-middle income Medicare beneficiaries aged 65 or older enrolled in the Pennsylvania Pharmaceutical Assistance Contract for the Elderly (PACE) program from 2003-2004. ${ }^{43}$ PACE participants paid copayments of $\$ 5-\$ 10$ with no deductibles, formularies, preferred drug lists, or prior authorization requirements. For a sample of 4,977 new clopidogrel users who had "complete health records" for the 3 years prior to clopidogrel initiation, Choudhry et al. searched all diagnoses recorded in Medicare claims data (Parts A and B) for evidence of indications for clopidogrel use. Only $47 \%$ of new clopidogrel users met "literature-based" 
criteria (hospitalization for ACS or PCI within previous 35 days or for stroke within previous 6 months; diagnosis of peripheral artery disease $[\mathrm{PAD}]$ in previous 3 years; hospitalization for upper gastrointestinal bleed within previous 3 years), and only $56 \%$ met "purposely broad" criteria that included 2 addtional categories: (a) any of the following at any point in the previous 3 years: hospitalization for ACS, stroke, or GI bleed, or coronary revascularization (PCI or coronary artery bypass graft [CABG] surgery), or diagnosis of PAD; and (b) any of the following in 30 days after the first clopidogrel claim: hospitalization for ACS or stroke, PCI or CABG, or diagnosis of PAD. A remarkably low 39\% of new clopidogrel users met U.S. Food and Drug Administration (FDA)-approved indications for its use. ${ }^{43}$

Putting into perspective the implications of their work for health care policy, Choudhry et al. suggested that clopidogrel "represents an increasingly common problem in pharmacotherapy: a newer, costly, branded product that is equivalent to an older, far less expensive agent for many patients but more effective for a well-defined subset of patients." Suggesting that the patients without indications for clopidogrel were "very likely prescribed this therapy for primary prevention," Choudhry et al. pointed to the Clopidogrel for High Atherothrombotic Risk and Ischemic Stabilization, Management, and Avoidance (CHARISMA) trial as evidence that patients without a clear indication for clopidogrel use might be exposed to unnecessary risk of harm. ${ }^{43-45}$ CHARISMA patients with "clinically evident atherothrombosis" $(n=12,153)$ randomized to clopidogrel plus aspirin experienced a "marginally significant reduction" in a composite rate of myocardial infarction, stroke or death from cardiovascular causes (6.9\% for clopidogrel+aspirin vs. $7.9 \%$ with for placebo+aspirin; relative risk $[\mathrm{RR}]=0.88 ; 95 \% \mathrm{CI}=0.77-0.998 ; P=0.046)$. However, among patients with "multiple atherothrombotic risk factors without documented cardiovascular disease" $(n=3,284)$ clopidogrel use was associated with increased rates of death from all causes $(5.4 \%$ for clopidogrel+aspirin vs. $3.8 \%$ for placebo+aspirin; $P=0.04$ ) and from cardiovascular causes $(3.9 \%$ vs. $2.2 \%$, respectively; $P=0.01) .^{44,45}$ Raising a number of possible biological explanations for the increased death rate associated with clopidogrel use in asymptomatic patients, study authors concluded that "whatever the explanation, it appears that until proven otherwise, clinicians should avoid dual antiplatelet therapy in patients without established vascular disease."44

In the Choudhry et al. sample, financial costs of potentially unnecessary use of clopidogrel were high; patients who failed to meet the "extended" criteria were dispensed a mean of 239 clopidogrel tablets at a cost of $\$ 937$ per patient per year (2005 dollars). Applying the rates of estimated "non-evidence-based" use in their sample to nationwide expenditures for clopidogrel, $\$ 3.5$ billion in 2005, Choudhry et al. suggested that "health care [payers] and individuals in the United States" potentially "spent almost $\$ 1.5$ billion in 2005 for clopidogrel in instances in which it ... has not been demonstrated to be superior to aspirin." ${ }^{23}$

\section{Prior Authorization and High-Stakes Games}

Clopidogrel had a discounted cost of $\$ 4.40$ per day at year-end 2008 , or $\$ 1,600$ per patient per year, enough by itself to push a Medicare Part D beneficiary about two-thirds of the way to the coverage gap ("donut hole") each year. ${ }^{46}$ Propelled by physician promotion and direct-to-consumer advertising, ${ }^{47}$ clopidogrel (Plavix) rang up $\$ 3.08$ billion in community pharmacy sales in the United States in 2007, making it the fifth-highest expenditure drug, up 38.1\% in sales from 2006 when it ranked seventh,$^{48}$ and up $146 \%$ in 5 years from sales of $\$ 1.26$ billion in 2002. ${ }^{49}$ And, clopidogrel is expected to be joined soon in the United States by prasugrel (Effient), ${ }^{50}$ which will push spending higher on newer drugs to prevent "clots."

In the face of the heavy promotion of Plavix and the growing promotion of Effient even before it is approved by the FDA, the assessment of the relationship of clopidogrel "PA" and cardiovascular outcomes in 1 Canadian province deserves a bright spotlight. But, even in dim light, one can see that the observational study by Jackevicius et al. should be viewed with a clear understanding of the pitfalls inherent in methodologies that measure events with coincident timing, which may or may not be causally related. The PA "removal" was really a change in the administrative process; the database did not capture all of the use of clopidogrel; and a multitude of factors including the coincident explosion in use of drug-eluting stents could explain the cardiovascular outcomes observed in the administrative claims data. The primary purpose of PA-targeting drug therapies in an efficient manner to those patients most likely to benefit and least likely to be harmed, while providing value for money for patients, third-party payers, and (in some cases) taxpayers - seems especially appropriate and evidence-based when applied to clopidogrel. While a great deal of money is riding on the outcome of the debate about the real value of PA interventions, more than money is at stake.

\section{Authors}

MARK A. JACKSON, RPh, BScPhm, BComm, is Provider Professional Services Liaison, Green Shield of Canada, Ontario. KATHLEEN A. FAIRMAN, MA, is Associate Editor and Senior Methodology Reviewer, and FREDERIC R. CURTISS, PhD, RPh, CEBS, is Editorin-Chief, Journal of Managed Care Pharmacy.

AUTHOR CORRESPONDENCE: Mark A. Jackson, RPh, Green Shield Canada, 8677 Anchor Dr., P.O. Box 1606, Windsor, Ontario N9A 6W1 Canada. Tel.: 519.739.1133, ext. 6215; E-mail: Mark.jackson@greenshield.ca 


\section{DISCLOSURES}

The authors report no conflicts of interest related to the subjects or products discussed in this article. Jackson is employed by a pharmacy benefits management company.

\section{REFERENCES}

1. Jackevicius CA, Tu JV, Demers V. Cardiovascular outcomes after a change in prescription policy for clopidogrel. N Engl J Med. 2008;359(17):1802-10.

2. World Health Organization. World Data Table. The Atlas of Heart Disease and Stroke. Available at: www.who.int/cardiovascular_diseases/en/cvd_ atlas_29_world_data_table.pdf. Accessed December 1, 2008.

3. Peck P. Easing access to antiplatelet drugs improved coronary stent outcomes. MedPage Today. October 22, 2008. Available at: www.medpagetoday. com/Cardiology/PCI/11420. Accessed November 19, 2008.

4. Anonymous. Policy change improves cardiovascular outcomes: Canadian removal of prior-authorization policy for clopidogrel beneficial to heart attack patients. Modern Medicine. October 22, 2008. Available at: www.modernmedicine.com/modernmedicine/Modern+Medicine+Now/Policy-ChangeImproves-Cardiovascular-Outcomes/ArticleNewsFeed/Article/detail/560649 Accessed November 19, 2008

5. Public Affairs Department, Western University of the Health Sciences. Faster medication $=$ fewer heart attacks, according to a new study published today in the New England Journal of Medicine. October 23, 2008. Available at: www.wsprod.westernu.edu/news/nr_detail. jsp?id=6282\&groupname=AllNews. Accessed November 19, 2008.

6. Cox C. Policy changes leads to better clopidogrel access, improved outcomes. Tctmd: The Source for Interventional Cardiovascular News and Education. Available at: www.tctmd.com/show.aspx?id=74846. Accessed November 19, 2008.

7. Fairman KA, Curtiss FR. Making the world safe for evidence-based policy: let's slay the biases in research on value-based insurance design. J Manag Care Pharm. 2008;14(2):198-204. Available at: www.amcp.org/data/jmcp/ JMCPMaga_March\%2008_198-204.pdf.

8. Ontario Ministry of Health and Long Term Care. Ontario Drug Benefit Formulary/Comparative Drug Index, Edition No. 38. Available at: www. health.gov.on.ca/english/providers/program/drugs/formulary_38/ed38_0_ bk.pdf. Accessed November 17, 2008.

9. Ontario Ministry of Health and Long Term Care. Ontario Drug Benefit Formulary/Comparative Drug Index, Edition No. 39. Available at: www. health.gov.on.ca/english/providers/program/drugs/formulary_39/ed39_0_ bk.pdf. Accessed November 25, 2008.

10. Ontario Ministry of Health and Long Term Care. 2003/2004 Report Card for the Ontario Drug Benefit Program. Available at: www.health.gov. on.ca/english/public/pub/ministry_reports/odb_report03/drug_rep.html. Accessed November 17, 2008

11. Ontario Ministry of Health and Long Term Care. 2001/2002 Report Card for the Ontario Drug Benefit Program. Available at: www.health. gov.on.ca/english/providers/pub/drugs/odb_reports/odb_rep_01_02.pdf Accessed December 3, 2008

12. State of Maine Department of Health and Human Services Maine Care/ MEDEL. Prior Authorization Form: Plavix. Available at: www.mainecarepdl org/index.pl/pafiles/pa---prior-authorization-forms/plavix.20715.1.doc. Accessed November 19, 2008

13. State of Pennsylvania Department of Public Welfare. Pharmacy prior authorization general requirements. Available at: www.dpw. state.pa.us/PartnersProviders/MedicalAssistance/DoingBusiness/ MAPharmProg/003675357.htm. Accessed November 19, 2008

14. CIGNA Pharmacy Services. CIGNA HealthCare Medication Prior Authorization Form. Available at: www.cigna.com/health/provider/medical/ forms/4_AZ_pa_form.pdf. Accessed November 19, 2008.
15. HealthSpring Formulary Exception/Drug Prior Authorization Form: Revised 8.23.06. Available at: www.healthspring.com/userfiles/ PharmacyContent/HSNATMEM371\%20PA\%20Form.pdf. Accessed November 19, 2008.

16. Oklahoma Health Care Authority. Prior Authorization. Available at: www.ohca.state.ok.us/providers.aspx?id<1218. Accessed November 19, 2008.

17. Scan Health Plan Express Scripts, Inc. Prior Authorization Request Form. Available at: www.scanhealthplan.com/documents/arizona/prior_ auth_pharmacy_enu.pdf. Accessed November 19, 2008.

18. Phillips CR, Larson LN. Evaluating the operational performance and financial effects of a drug prior authorization program. J Manag Care Pharm. 1997;3(6):699-706. Available at: www.amcp.org/data/jmcp/research v6_699-706.pdf.

19. Ontario Ministry of Health and Long Term Care. Ontario Drug Benefit Formulary/Comparative Drug Index, Edition No. 38, Update B effective September 4, 2003. Available at; www.health.gov.on.ca/english/providers/ program/drugs/formulary_38/38_b_ven_final.xls. Accessed November 17, 2003.

20. Laupacis A. Inclusion of drugs in provincial drug benefit programs: who is making these decisions, and are they the right ones? CMAJ. 2002;166(1):44-47.

21. Ontario Ministry of Health and Long Term Care. Request for Plavix (clopidogrel) Individual Clinical Review (Section 8). Form 4253-87. Available at: www.uwo.ca/cns/resident/tools/Section\%208.pdf. Accessed November 29, 2008.

22. Ontario Ministry of Health and Long Term Care. Ontario Drug Benefit Formulary/Comparative Drug Index, Edition No. 40. Available at: www. health.gov.on.ca/english/providers/program/drugs/formulary_40/edition_40. pdf. Accessed November 17, 2008.

23. Ontario Ministry of Health and Long Term Care. Publicly Funded Drug Programs. Available at: www.health.gov.on.ca/english/providers/program/ drugs/funded_drug/fund_trillium.html. Accessed December 4, 2008.

24. Paterson JM, Suleiman A, Hux JE, Bell C. How complete are drug history profiles that are based on public drug benefit claims? Can J Clin Pharmacol. 2008; 15(1):e108-16.

25. Personal communication with J. Michael Paterson, Institute for Clinical Evaluative Sciences, Toronto, ON. November 24, 2008.

26. Cook TD, Campbell DT. Quasi-Experimentation: Design and Analysis Issues for Field Settings. Boston: Houghton Mifflin Company; 1979. pp 209-14.

27. Tu JV, Bowen J, Chiu M, et al. Effectiveness and safety of drug-eluting stents in Ontario. N Engl J Med. 2007;357(14):1393-402. Available at: www. content.nejm.org/cgi/reprint/357/14/1393.pdf. Accessed November 29, 2008.

28. et al. Drug eluting stents: an economic evaluation [Technology overview no 15]. Ottawa: Canadian Coordinating Office for Health Technology Assessment; February 2005. Available at: www.cadth.ca/media/pdf/372_ drug_eluting_stents_ov_e.pdf. Accessed November 29, 2008.

29. Supplementary Appendix. Supplement to: Tu JV, Bowen J, Chieu M, et al. Effectiveness and safety of drug-eluting stents in Ontario. N Engl J Med. 2007;357(14):1393-402. Available at: www.content.nejm.org/cgi/ data/357/14/1393/DC1/1. Accessed November 29, 2008.

30. Data reported by Solucient (Thomson Healthcare, Ann Arbor, Michigan) show that there were 1,400 drug-eluting stents of 55,800 total stent procedures (2.5\%) in April 2003 and 33,400 of 60,800 total stent procedures (54.9\%) in December 2003. Anonymous. By the numbers. Modern Healthcare. March 8, 2004:9.

31. Love MP, Schampaert E, Cohen EA, et al. The Canadian Association of Interventional Cardiology and the Canadian Cardiovascular Society joint statement on drug-eluting stents. Can J Cardiol. 2007;23(2):121-23. Available at www.ccs.ca/download/position_statements/2007_10095_love.pdf. Accessed December 2, 2008 
32. Serebruany VL. Selective serotonin reuptake inhibitors and increased bleeding risk: are we missing something? Am J Med. 2006;119(2):113-16.

33. Glassman AH, Bigger, JT Jr. Antidepressants in coronary heart disease: SSRIs reduce depression, but do they save lives? JAMA. 2007;297(4):411-12.

34. Taylor CB, Youngblood ME, Cartellier D, et al. Effects of antidepressant medication on morbidity and mortality in depressed patients after myocardial infarction. Arch Gen Psychiatry. 2005;62(7):792-98. Available at: www. archpsyc.ama-assn.org/cgi/reprint/62/7/792. Accessed November 29, 2008.

35. Lange RA, Hillis DH. Antiplatelet therapy for ischemic heart disease. $N$ Engl J Med. 2004;350(3):277-80.

36. Bayer Low Dose (81 mg enteric-coated) aspirin. $\$ 10.99$ per 200 tablets at www.drugstore.com. Accessed November 30, 2008.

37. Discounted allowed charge before member cost share. Summary analysis of actual claims data for a large employer for the 3-month period of claims data through September 30, 2008.

38. Anonymous. Clopidogrel (Plavix) revisited. The Medical Letter. 2006;48(1232): 29-31.

39. Gleason PP. Assessing step-therapy programs: a step in the right direction. J Manag Care Pharm. 2007;13(3):273-75. Available at: www.amcp.org/ data/jmcp/273-75.pdf.

40. Curtiss FR. Outcomes of sword swallowing and pharmaceutical steptherapy interventions. J Manag Care Pharm. 2007;13(3):294-96. Available at: www.amcp.org/data/jmcp/284-86.pdf.

41. Mamdani M, Warren L, Kopp A, et al. Changes in rates of upper gastrointestinal hemorrhage after the introduction of cyclooxygenase-2 inhibitors in British Columbia and Ontario. CMAJ. 2006;175(12):1535-38. Available at: www.cmaj.ca/cgi/content/full/175/12/1535. Accessed November 18, 2008.
42. Baron JA, Sandler RS, Bresalier RS, et al. Cardiovascular events associated with rofecoxib: final analysis of the APPROVe trial. Lancet. 2008;372(9651):1756-64

43. Choudhry NK, Levin R, Avorn J. The economic consequences of nonevidence-based clopidogrel use. Am Heart J. 2008;155(5):904-09.

44. Bhatt DL, Fox KAA, Hacke W, et al. Clopidogrel and aspirin versus aspirin alone for the prevention of atherothrombotic events. N Engl J Med. 2006;354(16):1706-17.

45. Wang TH, Bhatt DL, Fox KAA, et al. An analysis of mortality rates with dual-antiplatelet therapy in the primary prevention population of the CHARISMA trial. Eur Heart J. 2007;28(18):2200-07.

46. Hoadley J, Hargrave E, Cubanski J, Neuman T. The Medicare Part D coverage gap: costs and consequences in 2007. Kaiser Family Foundation. Available at: www.kff.org/medicare/upload/7811.pdf. Accessed November 22, 2008.

47. Donohue JM, Cevasco M, Rosenthal MB. A decade of direct-to-consumer advertising of prescription drugs. N Engl J. Med. 2007;357(7):673-81. Available at: www.content.nejm.org/cgi/content/full/357/7/673. Accessed November 22, 2008.

48. Anonymous. Top 200 brand drugs by retail dollars in 2007. Data from Verispan VONA. Drug Topics. March 10, 2008:28.

49. Anonymous. Top 200 brand drugs by retail dollars in 2002. Data from Verispan Scott-Levin SPA. Drug Topics. April 7, 2003.

50. Goldstein J. Lilly dubs would-be Plavix rival "Effient." Wall Street J. January 4, 2008. Available at: www.blogs.wsj.com/health/2008/01/04/lillydubs-would-be-plavix-rival-effient/. Accessed November 22, 2008. 